\title{
A Comparative Study of Competencies of Doctors Working in Private \& Public Hospitals - An Indian Perspective
}

\author{
Sujit G. Metre and Muktai M. Chavan \\ Dr. Ambedkar Institute of Management Studies and Research, Nagpur, \\ Maharashtra, India
}

Received January 2017; Revised May 2017; Accepted June 2017

\begin{abstract}
The healthcare industry is a specific representative of the service industry that regards quality as a fundamental value of medical care. To manage quality within the healthcare setting is a challenging task due to its complexity. Further, when it comes to managing the ever-growing number of patients with limited number of health care professionals, a question mark is placed on the quality of the service provided. The role of doctors is pivotal in providing quality healthcare services to the patients. When an individual visits a doctor with some symptoms, it marks the beginning of a relationship of trust and confidence. A doctor not only treats the symptoms, but also tries to empathize with the patients. The process of treatment is marked by various meetings which are of two-way clear communication and effective interpersonal skills. The way the doctor communicates with the patient also plays a pivotal role in the healing process. Unfortunately, there has been a rise in the cases of physical attacks on the doctors by the patients and their relatives. The major area of concern is the lack of appropriate communication between the patients, relatives, and the doctors. We have taken up this study to understand the role of doctors and compare the competencies of doctors working in private and public hospitals. Further, we have also determined the relationship between the competency of doctors and the quality of service along with patient satisfaction. We used the survey method for collecting data from doctors, patients, and their relatives. The gap identified from the literature review suggests that comparative studies of competencies of health care professionals working with private and public hospitals were rarely done. Also, the Fundamental Interpersonal Relations Orientation (FIRO B) as a tool to gauge the interpersonal relations orientation of doctors in the context of research is tried for first time. The findings of the study can act as guidelines for government doctors and their private counterparts in understanding the skills necessary for effective doctorpatient relationship. The government-run hospitals will be able to work on areas of concern suggested by the researchers for delivering service quality to its patients.
\end{abstract}


Private hospitals, too, will be able to redesign their policies and practices to ensure the quality of services to their patients.

Keywords: Competency, doctors, private hospitals, government hospitals, service quality.

Reference to this paper should be made as follows: Metre, S. G. and Chavan, M. M. (2017). A Comparative Study of Competencies of Doctors Working in Private \& Public Hospitals - An Indian Perspective. ICPE Public Enterprise Half-Yearly Journal, 23(1), 16-30.

\section{Introduction}

Competence is a generic term referring to a person's overall capacity, while competency refers to specific capabilities, such as leadership (Chase, 2010). Having a competent workforce is the key to success of any organization. One can say that, almost everything can be replaced or repaired, but life cannot be. Health care is one such area where people's lives are at stake and, hence, the 'stakes' are high.

The health care deals with different services, such as hospital services, diagnosis services, physician consultancies, and some other emerging fields. What is important to understand is that the role of a doctor/physician is undeniably the most important one. Hence, in the present study, the focus is on the doctors/physicians who are the major component of the health care service. Competence or competency mapping framework ensures that doctors manage to keep themselves abreast of the latest technologies and satisfy the patients.

This paper attempts to differentiate between commonly interchanged but three very important and different terms: knowledge, skills, and competencies. The following Table 1 differentiates among these three terms.

Table 1

Difference between Knowledge, Skill, and Competency

\begin{tabular}{|c|c|c|}
\hline Knowledge & Skill & Competency \\
\hline $\begin{array}{l}\text { Knowledge is awareness, in- } \\
\text { formation, or understanding } \\
\text { about facts, rules, principles, } \\
\text { guidelines, concepts, theo- } \\
\text { ries, or processes needed to } \\
\text { successfully perform a task. }\end{array}$ & $\begin{array}{l}\text { A skill is a capacity } \\
\text { to perform mental or } \\
\text { physical tasks with a } \\
\text { specified outcome }\end{array}$ & $\begin{array}{l}\text { A competency may be } \\
\text { comprised of knowledge, } \\
\text { a single skill or ability, a } \\
\text { personal characteristic, or } \\
\text { a cluster of two or more } \\
\text { of these attributes. }\end{array}$ \\
\hline
\end{tabular}


A doctor can acquire knowledge by means of education, i.e., they can learn about the details of the profession by acquiring degrees, such as MBBS, MD, MS, DGO, BAMS, BHMS, etc. A doctor can hone their skills through practice until they become an inherent quality. But being competent means having the knowledge and the skill, plus any personal characteristic, such as interpersonal skills, patience, intuition, and listening skills.

In this light, the paper is interested in understanding the factors or attributes that affect the competency of a doctor. Specifically, the paper focuses on competencies of doctors working in private and government hospitals. To do this the paper employs the survey method, along with the Fundamental Interpersonal Relations Orientation (FIRO B) analysis.

The next section provides a brief background of the tools used, FIRO B and various competency models used in various countries with an overview of the related literature, which forms the basis for developing empirically tested hypotheses.

\section{Background and Literature Review}

Quality refers to the closeness of an actual outcome to the expected outcome by the observer (Kalepu, 2014). This observer has become the Customer, who has gained total control over the supplier of the service or product. Therefore, the onus is now on the service provider who must try to satisfy the customer by giving him/her the best possible outcome. Health care is one tricky sector, where it is highly challenging to take care of each and every aspect as the end user's very life is at stake. Health care service providers - private or government-owned - want now to provide quality services to the patients, as they now realize the importance of service quality as a measure to improve their competitive position. People no longer choose a hospital just because their physician advised them to do so or because it is located nearby. There are a variety of factors which now contribute to the selection criteria of a hospital. Improvements in global health can only be realized through the development of a workforce that has been educated to promote health and to care for those with disease. Increased attention is being placed on competency-based education as a means for optimizing the preparation of health professionals.

The customers' expectations are derived from their perception of their previous experiences in the use of services. According to Grönroos (2001), service quality is the difference between customer expectations and perceptions as the service is being received by the customer (Parasuraman et al., 1988; Irfan \& Ijaz, 2011). Thus, it is necessary for healthcare providers to monitor how well the customers' expectations have been met after delivering the services (Zarei, Arab, Froushani, Rashidian, \& Tabatabaei, 2012). 
The General Assembly of the International Association of Medical Regulatory Authorities (IAMRA) meeting in Melbourne, Australia, passed a resolution encouraging regulators to introduce systems that will make sure doctors can show they are competent and up to date from the day they qualify to the day they retire. ("Doctors face competency checks throughout the world", 2016). The Accreditation Council for Graduate Medical Education (AGME) expects residents to obtain competency in the six areas to the level expected of a new practitioner Patient Care, medical knowledge, interpersonal and communication skills, Professionalism, Practice-Based Learning and Improvement and Systems-Based Practice (Kavic, 2002).

In providing responsive and quality health care delivery, the importance of understanding patients' satisfaction is widely acknowledged. According to Woodside, Frey, and Daly (1989), cited in Peprah (2014), consumer satisfaction is a fundamental requirement for healthcare providers. Many studies add that in addition to its positive implications on patient retention and loyalty, patient satisfaction influences the rate of patient compliance with physician advice and the healing process of patients (Calnan, 1988; Roter, Hall, \& Katz, 1987). A competency model for general practice, comprising implications for selection, training, and development (Patterson, Ferguson, Lane, Farrell, Martlew, \& Wells, 2000), suggests that effective communication is crucial to the medical job role, in general, and for general practice, in particular.

There are a number of critical issues relating to healthcare services that highlight the need to assess and measure patients' satisfactions and improve them. Much has been said about service quality and its importance in today's world where consumers question each and every aspect of service delivered to them. Healthcare is one such industry where quality is a fundamental value to medical care. To manage quality in India, where we follow a three-tiered delivery system to lakhs of patients who belong to various strata of society becomes quite challenging. With rise in number of private players providing healthcare facilities to the common man, it becomes imperative to understand the service quality provided to the patients and their relatives. Most of the literature on service quality in health care examines the perception using the SERVQUAL model.

Peprah and Atarah (2014) conducted a study on assessing the patients' satisfaction using SERVQUAL in a hospital in Ghana and suggested that four out of the six SERVQUAL model dimensions, namely reliability, communication /interpersonal relationship, assurance, and responsiveness, were to be taken care of as the patients showed their dissatisfaction. Yousapronpaiboon and Johnson (2013) studied the service quality between private and public hospitals in Thailand and found that the poor service quality delivered to patients by public hospitals as compared to the private hospitals is due to five dimensions of service quality: responsiveness, reliability, empathy, tangibility, and assurance, respectively. The foregoing discussion leaves us with a broad idea about the variables highlighted in the literature as determinants 
of service quality. However, we go beyond the related literature and complement it with the realities of the corporate and non-corporate hospitals and the various policy initiatives that the government of India has taken in order to provide quality health care services.

Maharashtra is the name of the third-biggest state of India. Mumbai (Bombay) is the capital of Maharashtra. Vidarbha is the eastern region of Maharashtra state, which is made up of the Nagpur Division and the Amravati

Division. It occupies $31.6 \%$ of the total area and holds $21.3 \%$ of the total population of Maharashtra. The largest city in Vidarbha is Nagpur. Nagpur, the second capital of Maharashtra, boasts of three medical colleges and hospitals, plus nursing institutes and is becoming a medical hub with a rise in the number of hospitals like Alexis, Wockhardt, and AIIMS. With the scenario looking so opportunistic, there is a scope for development. We intend to study the competencies of doctors working in public and private hospitals in the Vidarbha region. In the next section, we discuss the methodology employed and the data sources for the variables used in the paper.

\section{Methodology}

\section{Research Setting}

The following model (Figure 1) and tools were adopted for the current research. The model considers that a "better competence of the health care professional" leads to a "better service quality", which in turn leads to "better reputation \& success" of the hospitals.

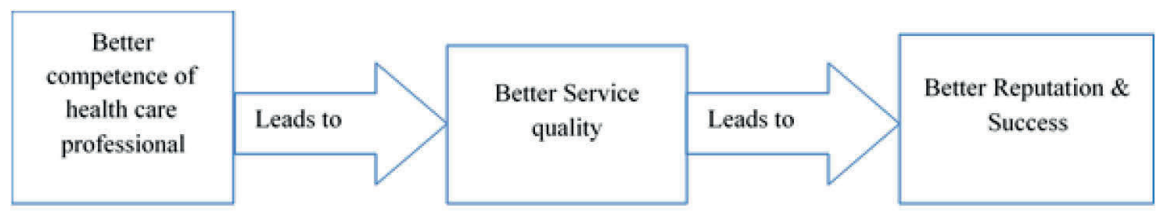

Figure 1. Conceptual model for research.

\section{Variables and Measurement}

Competency mapping is used to match the capabilities and talent of personnel with specific job tasks and organizational needs. Common competency mapping approaches include assessment center, critical incidents technique, interviewing, questionnaires, and psychometric tests. We designed a Competency mapping ques- 
tionnaire which had the independent and control variables divided into five basic categories.

First, Basic Knowledge and Information that a doctor must possess in order to treat the patients; this category includes five sub-factors, namely Command of basic facts, Relevant professional knowledge, Diagnostic testing, Documentation, and Safety \& infection control.

Second, Skills and Attributes of a doctor, which have a significant impact on the doctor-patient relationship. These are further subdivided into five sets, namely Continuing sensitivity to events, Analytical, problem solving and decision-making skill, Social skills and abilities, Emotional resilience, and Pro-activity.

Third, Communication and Interpersonal skills, which are the most important part of the health care delivery system in India, as the people here belong to different religions, communities, cultures, and speak different languages. This category includes Listening skills, Precision in communication, Sensitivity, Team spirit, Flexibility, and being Receptive to corrections.

Fourth, Personal Qualities, which include High energy level, Detail consciousness, Honesty, and Adherence to code of conduct.

Fifth, and the last determinant, is Meta Qualities, which comprise Creativity, Mental agility, Balanced learning habits, and Skills and self-knowledge.

Along with the above, the paper also used FIRO B as a tool for better understanding of one's self in a number of important areas, including how to handle interpersonal relationships, and one's own social needs, how others perceive you, and how you see them. The theory is based on the belief that when people get together in a group, there are three main interpersonal needs they are looking to obtain - affection/openness, control, and inclusion. Schutz (1958) developed a measuring instrument that contains six scales of nine-item questions that he called FIRO-B. These categories measure how much interaction a person wants in the areas of socializing, leadership and responsibilities, and more intimate personal relations. Element-B (former known as 'FIRO-B') was created, based on this theory, a measurement instrument with scales that assess the behavioral aspects of the three dimensions. Scores are graded from 0-9 in scales of expressed and wanted behavior, which define how much a person expresses to others, and how much he wants from others. A doctor's interpersonal skills have a major impact on his relationships with his patients and this in turn can affect the patient satisfaction as well. Competencies are captured by administering a structured questionnaire and by performing a FIRO B analysis of a sample of health care professionals.

Service quality is captured by administering the SERVQUAL questionnaire on patients and their relatives. Five parameters were measured using 25 sub-questions, thus allowing the maximum SERVQUAL score of 175.

In-depth structured interviews of senior doctors were conducted to understand the skills that distinguish a successful doctor from an unsuccessful one. The focus of the 
interviews was to understand the course content and the pedagogy used to impart these skills and beliefs they have about treating the patients.

The reputation and success of the hospital is captured using observation and other supporting data, such as information about the infrastructure, the consultation fees, percentage of patients admitted, and availability of experienced professionals. Each of these are measured on a three-point scale, thus making the highest possible score of 12 .

\section{Research Hypotheses}

When it comes to the diagnosis of a case, a doctor must be able to give due consideration to many factors and one of them is taking opinions or accepting suggestions from seniors or colleagues. If doctors are too adamant in not accepting the view of others, it may lead to a wrong diagnosis and ultimately it will affect the quality of the service being provided. And it will surely affect the patients. The FIRO B analysis allows us to check the expressed and wanted control parameters of the doctors. In this regard, the following hypothesis is put forward:

- Ho1: There is no significant difference between the expressed control parameter and the wanted control parameter for doctors.

The SERVQUAL score captures the patient satisfaction and there should not be any difference in the level of satisfaction between the patients visiting the public and private hospitals and therefore the second hypothesis is:

- Ho2: The average SERVQUAL scores of doctors from state-owned hospitals equals the average SERVQUAL scores of doctors from private hospitals.

The success and reputation of a public and private hospital should be independent of ownership. Therefore, the third hypothesis is:

- Ho3: The average success and reputation score (SRS) of the doctors from state-owned hospitals equals the average SRS of doctors from private hospitals.

The patient satisfaction and reputation of a hospital should be interrelated. Therefore, the fourth hypothesis is:

- Ho4: There is no significant relationship between the SERVQUAL score and the success and reputation score (SRS) of state-owned hospitals and private hospitals. 


\section{Data Selection and Sources}

A total of 102 hospitals from Vidarbha region are considered as the universe of the proposed study. These were the hospitals having a minimum 100 beds and were spread across 11 districts of the Vidarbha region. The sampling framework is described below, in Figure 2.

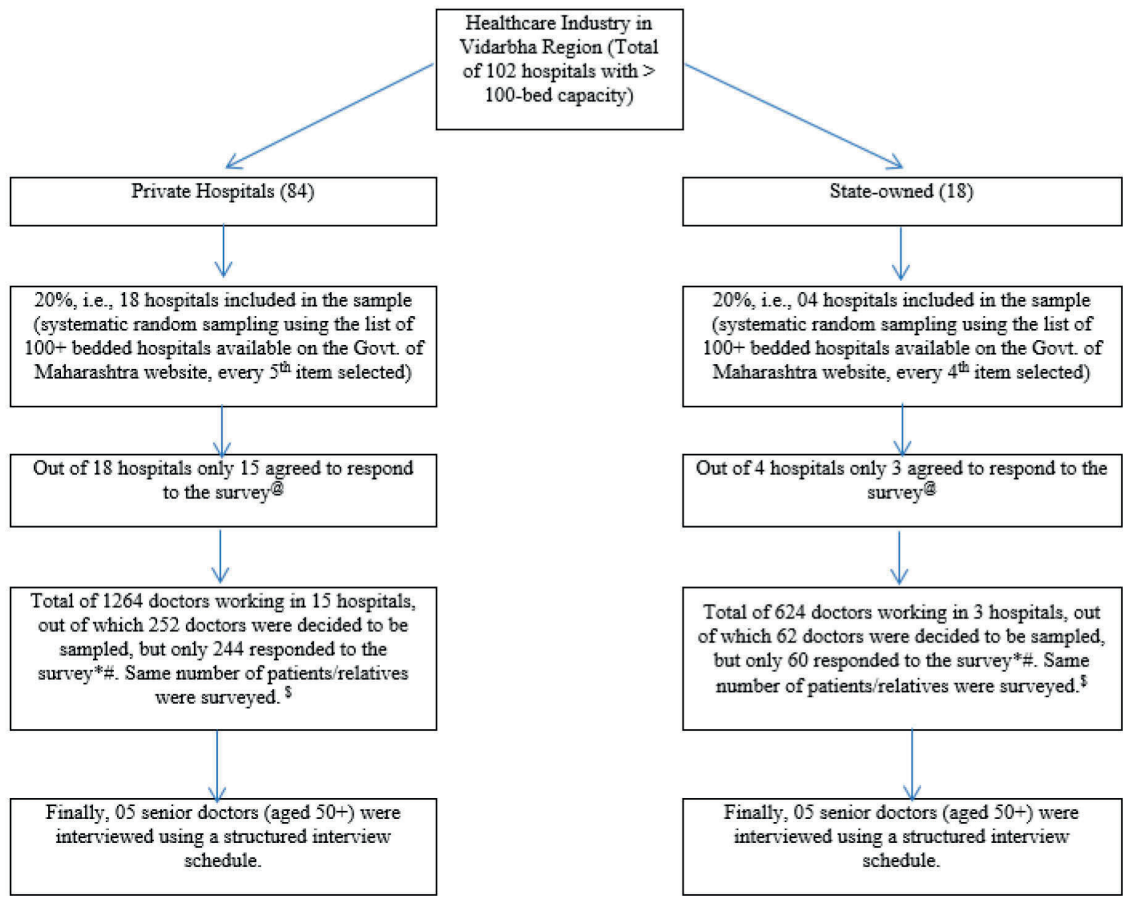

Note.@Observation; * Competency mapping questionnaire; \# FIRO B; \$ SERVQUAL questionnaire.

Figure 2. Sampling frame.

\section{Hypothesis Testing and Analysis}

Levene's Test for Equality of Variances (Table 2) lets us conclude that there are equal variances assumed and the independent sample t-test for Equality of Means suggest us that:

A In the case of state-owned hospitals, there is no significant difference be- 
tween the expressed control parameter and the wanted control parameter for doctors. Here, the doctors were ready to take opinions of others and accept the offered suggestions.

B In the case of private hospitals, there is a significant difference between the expressed control parameter and the wanted control parameter for doctors. Here, the doctors do not want others to control their behavior. This can create problems for doctors if they are working in teams, which they generally have to do in big multispecialty hospitals.

The Levene's Test for Equality of Variances makes us assume unequal variances and a p-value of 0.244 (Table 2) lets us accept the null hypothesis and conclude that the average scores of doctors from state-owned hospitals are equal to the average scores of doctors from private hospitals.

Table 2

Statistics - Testing Hol and Ho2

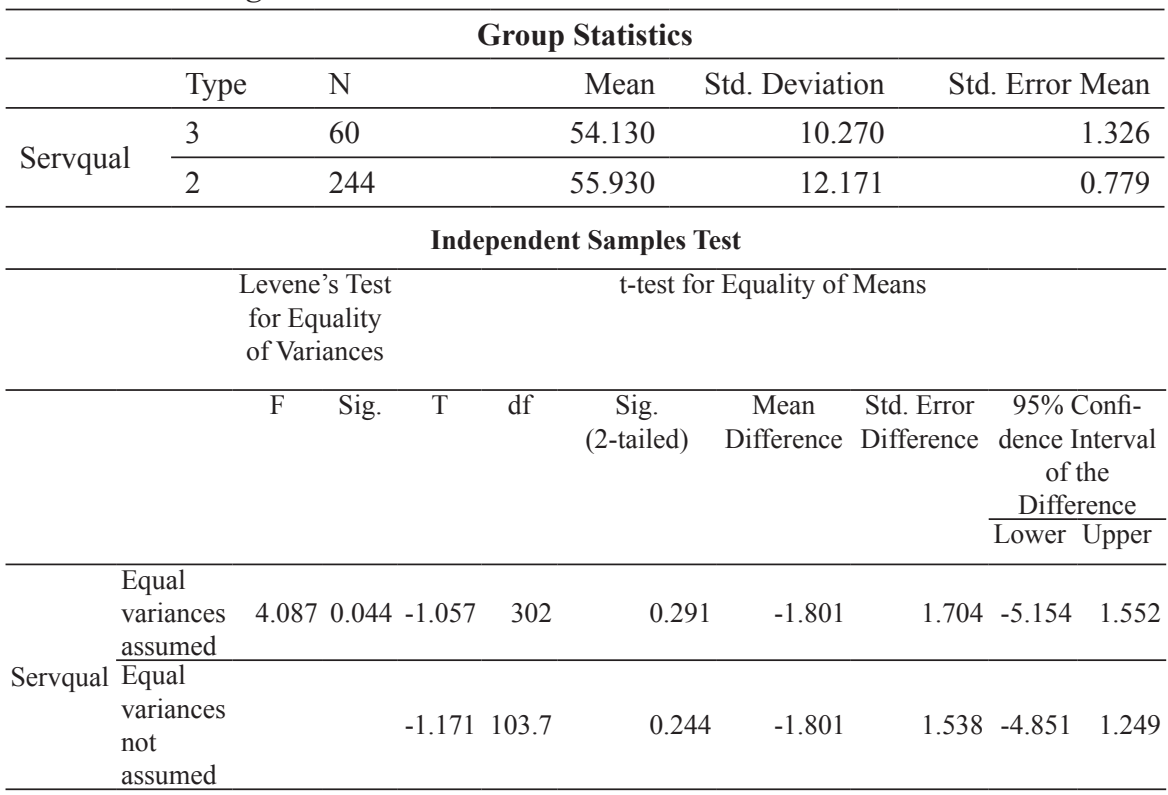

Furthermore, the Levene's Test for Equality of Variances makes us assume equal variances and a p-value of 0.000 (Table 3 ) lets us reject the hypothesis that the average success and reputation score (SRS) of doctors from state-owned hospitals equals the average SRS of doctors from private hospitals. 
Table 3

Statistics - Testing Ho3

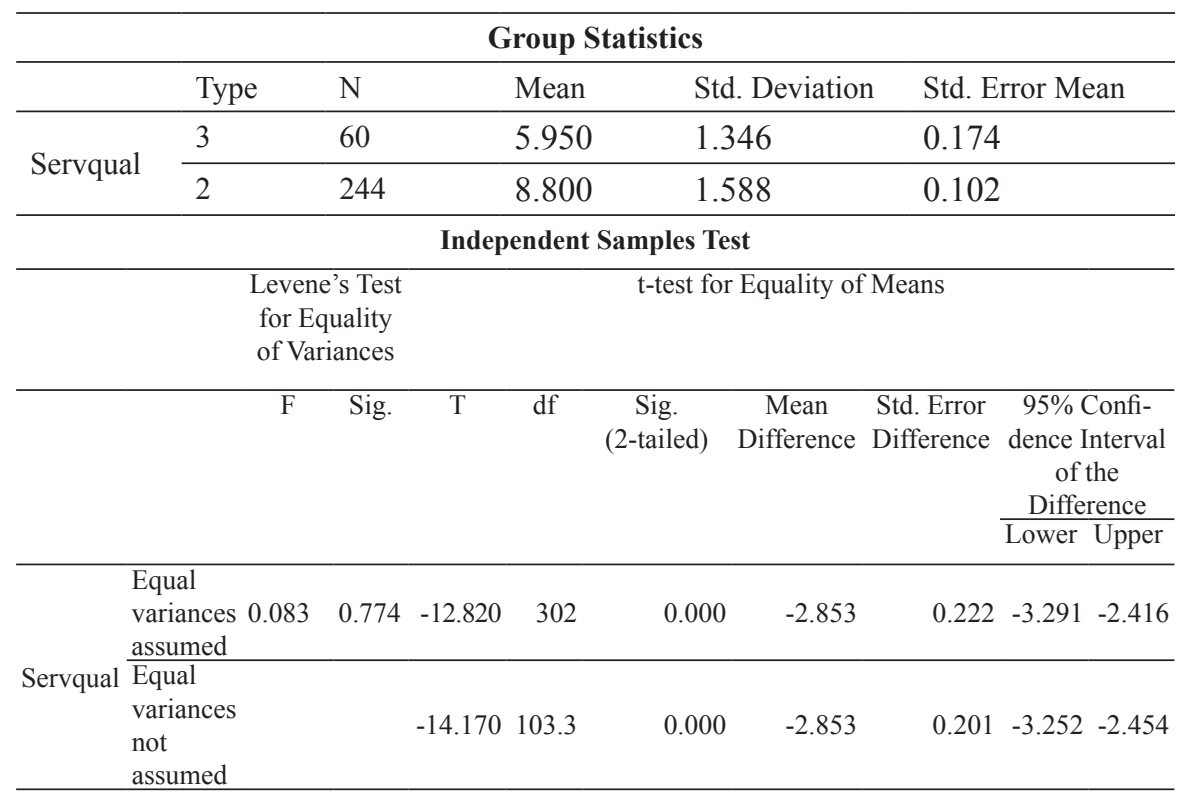

The Kendall's tau_b Correlation Coefficient (0.010) is low and significant, and Spearman's rho (0.014) is also low and significant (Table 4). Thus, we find that the results are contrasting with the assumption that the patient satisfaction should have a direct relation with the reputation of the hospital. Here, we accept the null hypothesis and conclude that there is no relationship between the SERVQUAL score and SRS.

Table 4

Statistics - Testing Ho4

\begin{tabular}{|c|c|c|c|c|}
\hline \multicolumn{5}{|c|}{ Correlations } \\
\hline & & & SRS & Servqual \\
\hline \multirow{6}{*}{ Kendall's tau_b } & \multirow{3}{*}{ SRS } & Correlation Coefficient & 1.000 & 0.100 \\
\hline & & Sig. (2-tailed) & & 0.815 \\
\hline & & $\mathrm{N}$ & 304 & 304 \\
\hline & \multirow{3}{*}{ Servqual } & Correlation Coefficient & 0.010 & 1.000 \\
\hline & & Sig. (2-tailed) & 0.8 & \\
\hline & & $\mathrm{N}$ & 304 & 304 \\
\hline \multirow{5}{*}{ Spearman's rho } & \multirow{3}{*}{ SRS } & Correlation Coefficient & 1.000 & 0.014 \\
\hline & & Sig. (2-tailed) & . & 0.807 \\
\hline & & $\mathrm{N}$ & 304 & 304 \\
\hline & \multirow[b]{2}{*}{ Servqual } & Correlation Coefficient & 0.014 & 1.000 \\
\hline & & $\begin{array}{l}\text { Sig. (2-tailed) } \\
N\end{array}$ & $\begin{array}{r}0.807 \\
304\end{array}$ & 304 \\
\hline
\end{tabular}




\section{Analysis of the In-Depth Structured Interviews}

In-depth structured interviews were designed for doctors, consisting of 17 questions which were intended to elicit responses in areas such as communication skills, interpersonal skills, the routine of doctors, relationships with colleagues and supervisors, personality traits, factors that motivate doctors, new learnings and aspects most or least liked by the patients. These skills are those skills which are not entirely taught in the curriculum practiced by the medical schools. This paper aims to bring out those skills that are found in a successful doctor.

For example, a senior doctor with 30 years of experience said that "it's of crucial importance to ease the patient. It is then you can establish a way to communicate and understand the problem. Unfortunately, the curriculum and pedagogy do not focus on this aspect."

Another doctor mentioned that "a good doctor is one who can feel the patients' plight, can explain to the relatives the problem, and how the treatment works. This communication has great impact on building faith and speeding recovery".

A third doctor said that "in government hospitals, our patience is tested most of the times, as the patients are mostly illiterate. To cope up with them, we need to keep calm and at the same time be very effective in communication."

A person going to a doctor is already suffering from some problem or another. A rude or cold behavior will surely aggravate his/her problems. In this sense, one of the doctors said that "patients expect us to explain the issue in simple terms. Sometimes due to work pressure, we may give a cold shoulder but then that results in many conflicts. We should be trained to respond rather than react in such a way."

When asked about the things liked most in a doctor by the patients, the following responses were elicited:

- Interpersonal skills

- Positive attitude

- Communications skills

- Pocket-friendly approach

- Style/looks

- Quick and accurate diagnosis

- Patience

- Soothing and calm nature

- Availability/Approach 
to time, hospitals must measure patient satisfaction and keep a tab on the lacunas found. Honing the interpersonal and communication skills of healthcare professionals is the need of the hour and the administrators must arrange for training inputs in this area. Secondly, there are implications for the doctors. A successful doctor is not only one who has the necessary medical qualifications; but rather he/she is one who along with his/her professional knowledge also possesses basic competencies like communication \& interpersonal skills. Most of the conflicts between a doctor and a patient happen because of poor communication. The doctors can understand their personal style of interaction and make changes in their way of interaction, to be able to satisfy and treat the patient. Thirdly, there are managerial implications for the Board of Studies members. Along with technical skills, other soft skills should be included in the curriculum for those who are pursuing a medical education.

The present study also has some limitations. In this sense, we were not able to get an equal number of doctors from some of the fields, such as Homoeopathy, Unani, and Ayurveda, among others. The same was the case with a number of public and private hospitals, as the number was more skewed in favor of private hospitals.

The present research, however, does not end with the conclusions provided herewith. The research can be made practice-specific. In health care, the role played by doctors is undoubtedly important, but at the same time, one cannot deny the importance of other health care professionals, such as nurses, technicians, and pharmacists. The study can be further extended to determine the competencies of these professionals.

\section{References}

Calnan, M. (1988). Towards a conceptual framework of lay evaluation of healthcare. Social Science and Medicine, 27(9), 927-933.

Chase, L. K. (2010). Nurse manager competencies. PhD (Doctor of Philosophy) thesis, University of Iowa. Retrieved from http://ir.uiowa.edu/etd/2681

Doctors face competency checks throughout the world. (4 October 2016). Retrieved 15 December 2016 from http://www.gmc-uk.org/news/29293.asp

Patterson F., Ferguson, E., Lane, P., Farrell, K., Martlew, J., \& Wells, A. (April 2000). A Competency Model for General Practice: Implications for Selection, Training, and Development. British Journal of General Practice, 50(452), 188-193.

GrÖnroos, C. (1984). A service quality model and its marketing implications. European Journal of Marketing, 18, 36-44.

GrÖnroos, C. (2001). The perceived service quality concept - a mistake. Managing Service Quality, 11(3), 46-55.

Irfan, S. M., \& Ijaz, A. (2011). Comparison of service quality between private and public hospitals: Empirical evidences from Pakistan. Journal of Quality and Technology Management, 4(1), 1-22.

Kalepu, R. (2014). Service Quality in Healthcare Sector: An Exploratory Study on 
The next question was related to the things which were least liked in a doctor by the patients. The following responses were elicited:

- Giving less information to the patient/relatives

- Cold/rude behavior

- Lack of availability

- Lack of professionalism

Thus, apart from professional skills, a successful healthcare professional must develop behavioral and interpersonal skills. Time management skills were also emphasized. The curriculum and pedagogy must focus on communication skills and personality development. Sustained training must be provided for these professionals throughout their careers.

\section{Findings and Conclusion}

Voltaire once said that the "art of medicine consists of amusing the patient while nature cures the disease." What Voltaire said might have been true several years back when man had no access to new technologies or had not discovered some lifesaving drugs. But nowadays, when the complexity of the diseases has increased, the population is growing, and ignorance is still rampant in a country like India, the question is, "does the nature really do the healing?" Perhaps yes or perhaps no. The true answer lies in the healthcare professionals and their competencies. The present study aimed to find out the competencies of doctors working in state-owned and private hospitals. We used various tools and methods of data collection and concluded that the state-owned hospital doctors are more flexible and open to other people's ideas. Surprisingly, the patients from both setups are satisfied equally, but the SRS scores reveal that in the Indian context, the private hospitals are having better reputation and success. Much of the SRS scores can be attributed to the technology and facilities available at private hospitals in India.

In-depth structured interviews provided the much-needed information regarding the skills of the doctors, their practices, beliefs, and routines. The most prominent skill that came out was communication \& interpersonal skills. Contrary to the belief that professional knowledge or basic knowledge will be the most preferred skill by the patients, results show that doctors' communication \& interpersonal skills, such as honesty and intuition, are preferred. Though most of the doctors have a very tough routine, they unanimously opined on the need of other skills necessary for effective medical practice, such diagnosis \& treatment. Thus, both professional \& behavioral competencies of doctors are very important for the success of a hospital and also for better service quality.

Managerial implications are threefold. Firstly, for hospital administrators, this study provides guidelines for ensuring a better service quality to the patients. From time 
Hospitals. The IUP Journal of Marketing Management, 13(1), 7-28.

Yousapronpaiboon, K., \& Johnson W. C. (2012). A Comparison of Service Quality between Private and Public Hospitals in Thailand. International Journal of Business and Social Science, 4(11), 176-184.

Kavic, M. S. (2002). Competency and the Six Core Competencies. JSLS: Journal of the Society of Laparoendoscopic Surgeons, 6(2), 95-97.

Peprah, A. A. (2014). Determinant of Patients' Satisfaction at Sunyani regional Hospital, Ghana. International Journal Business and Social Research (IJBR), 4(1), 96108.

Peprah, A. A., \& Atarah, B. A. (2014). Assessing Patient's Satisfaction Using SERVQUAL Model: A Case of Sunyani Regional Hospital, Ghana. International Journal of Business and Social Research (IJBSR), 4(2), 133-143. Retrieved 25 December 2016 from www.thejournalofbusiness.org

Roter, D. L., Hall, J. A., \& Katz, N. R. (1987). Relations between physicians, behaviors and analogue patients' satisfaction, recall, and impressions. Medical Care, 25(5), 437-451.

Schutz, W. C. (1958). FIRO: A three-dimensional theory of interpersonal behavior. New York, NY: Holt, Rinehart, and Winston.

Woodside, A. G., Frey, L. L, \& Daly, R. T. (1989). Linking service quality, customer satisfaction, and behavioural intention. Journal of Healthcare Marketing, 9(4), 5-17. Zarei, A., Arab, M., Froushani, A., Rashidian, A., \& Tabatabaei, S. (2012), Service quality of private hospitals: The Iranian patients' perspective. Health Services Research, 12(31), 1-7. Retrieved 15 December 2016 from http://www.thejournalofbusiness.org/index.php/site/article/viewFile/404/346

\section{Authors Note}

The authors would like to thank the special issue editor; the language editor of the journal; and the anonymous referees for their valuable feedback, which helped us to improve the quality of the paper significantly.

Correspondence concerning this article should be addressed to Sujit G. Metre, Dr. Ambedkar Institute of Management Studies \& Research, VIP Road, Deekshabhoomi, Nagpur, Maharashtra 440010, India. Email: sujit_metre@yahoo.com

\section{Biographical Notes}

Sujit G. Metre is a Former Director \& Professor, Dr. Ambedkar Institute of Management Studies \& Research, Deekshabhoomi, Nagpur, India. In the past, he helmed the Datta Meghe Institute of Management Studies as a Director. He has to his credit many research papers published in national and international journals. He is also a SEBI empaneled FE trainer and has conducted 100+ sessions for various institutes. 
He has been a corporate trainer for various private \& state-owned organizations, including the Public Health Institute, Nagpur. He has been actively supporting various NGO's and helping them by organizing awareness programs for them.

Muktai M. Chavan Deb is an Assistant Professor at Dr. Panjabrao Deshmukh Institute of Management Technology \& Research, Nagpur, India, with a total of 11 years of teaching experience. She holds a Master's degree in Clinical Psychology and an MBA. She has been invited as a Guest Speaker in many prestigious organizations, such as Power Grid and WCL, for training programs. Her area of interest is Health Care Management and Organizational Behavior. 